\title{
Taguchi Loss Function for Varus/Valgus Alignment in Total Knee Arthroplasty
}

\author{
Srinu Kusuma, Andrew G. Urquhart and Richard E. Hughes*
}

Laboratory for Optimization and Computation in Orthopaedic Surgery, Department of Orthopaedic Surgery, University of Michigan Medical School, Ann Arbor, MI, USA

\begin{abstract}
Methods of designing equipment to improve quality have been developed by Taguchi. A key feature of these methods is the development of loss function, which quantifies the financial cost (loss) resulting from deviations from target dimensions. Total knee arthroplasties can fail due to prosthetic component malalignment. A Taguchi loss function for varus/valgus alignment of the prosthesis and revision rates was developed. Six studies were identified from a comprehensive literature search. Varus and extreme valgus alignments correlated with an increased percentage of prosthetic failure. A loss function of $L(y)=\$ 326.80 y^{2}$, where y was deviation from ideal varus/valgus angle, was determined. The expected loss function was $E(L)=\$ 326.80\left(y^{2}+\mathrm{s}^{2}\right)$, where $\bar{y}$ was the mean deviance from the ideal varus/valgus angle and $s^{2}$ was the variance in varus/valgus angle. This loss function was used to estimate the cost savings of using computer-assisted surgical navigation in total knee arthroplasty (TKA). The average savings of a navigated TKA versus a conventional TKA, based on the expected loss equation derived from the Taguchi loss function, was $\$ 2,304$ per knee. The expected loss function derived here can serve as a tool for biomedical engineers seeking to use Taguchi quality engineering methods in designing orthopaedic devices.
\end{abstract}

Keywords: Total knee arthroplasty, Taguchi loss function, varus alignment, valgus alignment.

\section{INTRODUCTION}

Although healthcare has adopted some techniques for improving quality of care from manufacturing (Total Quality Management and Six Sigma), medicine has not utilized all of the important developments of statistically-based quality improvement methods developed in industry. For example, the methods developed by Dr. Genichi Taguchi [1] in the 1980 s for incorporating quality considerations in the design phase have not been widely applied to biomedical device design, especially in orthopaedic applications. A central part of Taguchi's theory was the development of a "loss function" that relates a part's deviation from an ideal target value, as opposed to a range of acceptable values, to an increased monetary cost to society. This loss is a continuous function; the further a product's characteristic varies from the "proper" values, the greater the loss. Taguchi's methods have proven useful in non-healthcare industries; biomedical engineers engaged in medical device design should also be able to benefit from Taguchi's ideas. The long-term objective of this research is to develop tools that can be used by orthopaedic implant designers to improve the quality of patient care and improve outcomes for total knee arthroplasty (TKA) surgery.

Therefore, the specific objective of this project was to develop a Taguchi expected loss function for varus/valgus alignment of the femoral TKA component.

*Address correspondence to this author at the Department of Orthopaedic Surgery, University of Michigan, 2019 BSRB, 109 Zina Pitcher Pl., Ann Arbor, MI 48109-2200, USA; E-mail: rehughes@med.umich.edu

\section{MATERIALS AND METHODOLOGY}

Data from the published literature were used to estimate the parameters of Taguchi's loss function for TKA. The derivation of the loss function assumes that there is a nonlinear relationship between the deviation from the target value of a design parameter and cost to society (per unit of production) [1]. Taguchi then used a second-order Taylor series expansion of that relationship to develop an approximation that he argued design engineers can use. The Taguchi loss function is

$$
L(x)=k(x-m)^{2}
$$

where $k$ is a constant of proportionality, $x$ is the actual value of the parameter realized during production of the part, and $m$ is the target value of the parameter. In the TKA application, $L$ is hospital cost, $x$ is the tibiofemoral angle after the prosthesis is implanted (the "production" process modeled here is the TKA surgery), and $m$ is the target tibiofemoral angle. Since the clinically accepted value for $m$ is six degrees, substitute $y=x-6$. This gives a loss function of $L=k y^{2}$, where $y$ is the deviation from the ideal tibiofemoral angle. Due to the quadratic form of this approximation, it is possible to derive an expression for the expected loss (per unit) in terms of the mean, variance, and target of the parameter [1]:

$$
E(L)=k\left[\bar{y}^{2}+\mathrm{s}^{2}\right]
$$

where $E(L)$ is the expected loss per unit. $\bar{y}$ and $\mathrm{s}^{2}$ are the mean and variance of the deviation from 6 degrees of valgus 
tibiofemoral angle in a population of patients having primary TKA surgery, respectively.

A comprehensive literature search was conducted for all clinical studies in English and non-English languages that assessed varus and valgus alignment after total knee arthroplasty and revision rates. A total of six studies [2-7] were identified from 1979 to 1994 . The characteristics of the studies are presented in Table $\mathbf{1}$. Revision rate data published in these studies were converted to probabilities of revision. These probabilities were tabulated with the respective varusvalgus alignment angles. If a revision rate was reported for a range of angles, the midpoint of the range was used in the development of the loss curve. Data in the extreme ranges, given only as greater than or less than a certain angle, were not included.

A plot of the deviation from the ideal tibiofemoral angle, with valgus angles as positive values and varus angles as negative values, versus the probability of revision was created for the six studies. Overall, any varus alignment and extreme valgus alignments correlated with an increased percentage of prosthetic failure and higher revision rates. A quadratic cure was fit to the data using a least-squares method. This curve has a vertical offset that represents a baseline probability of revision due to other patient characteristics that are independent of the alignment. The average cost per case for a given alignment angle was computed by multiplying each probability of revision and the average total hospital cost per case for an aseptic revision surgery $(\$ 55,911)[8]$.

\section{RESULTS}

The relationship between the probability of revision and tibiofemoral angle is shown in Fig. (1). The loss for each TKA surgery using the Taguchi formulation is plotted in Fig. (2) and is expressed mathematically as

$$
L(y)=\$ 326.80 y^{2}
$$

where $y$ is deviation from ideal varus/valgus angle. As the TKA deviates from the target alignment, the hospital incurs

Table 1. Individual Study Characteristics

\begin{tabular}{|c|c|c|c|c|c|c|c|c|}
\hline Author & $\begin{array}{l}\text { Yr } \\
\text { Published }\end{array}$ & $\begin{array}{l}\text { Yrs } \\
\text { Studied }\end{array}$ & $\begin{array}{l}\text { Yrs } \\
\text { Post-Op }\end{array}$ & $\begin{array}{l}\text { Study } \\
\text { Size }\end{array}$ & Demographics & Surgery & Methods & Failure Criteria \\
\hline $\begin{array}{l}\text { Ritter, } \\
\text { et al. [2] }\end{array}$ & 1994 & $\begin{array}{l}1975- \\
1983\end{array}$ & $1-13$ yrs & $\begin{array}{l}351 \text { knees } \\
\text { with >1yr } \\
\text { follow-up }\end{array}$ & $\begin{array}{l}\text { Only knees with }>1 \mathrm{yr} \\
\text { follow-up; Out of total } 421 \\
\text { surgeries: } 113 \text { bilateral; } 257 \\
\text { women; } 253 \text { with OA, } 10 \\
\text { with osteonecrosis, } 60 \text { with } \\
\text { RA }\end{array}$ & $\begin{array}{l}\text { Posterior cruciate } \\
\text { condylar TKA }\end{array}$ & $\begin{array}{l}\text { Standing AP } \\
\text { radiographs at } 1 \mathrm{yr}\end{array}$ & Revision or loosening \\
\hline $\begin{array}{l}\text { Jeffrey, } \\
\text { et al. [3] }\end{array}$ & 1991 & $\begin{array}{l}1976- \\
1981\end{array}$ & $>8$ years & $\begin{array}{l}115 \text { knees, } \\
102 \\
\text { patients }\end{array}$ & $\begin{array}{l}\text { All patients at Queens } \\
\text { Alexander Hospital under } \\
\text { one surgeon; excluded if no } \\
\text { pre-op or post-films, or } \\
\text { post-op death due to PE }\end{array}$ & Denham prosthesis & $\begin{array}{l}\text { Radiographs at full } \\
\text { extension }\end{array}$ & $\begin{array}{l}\text { 1)Revision for loosening, or } \\
\text { 2) showed definite clinical } \\
\text { and radiological signs of } \\
\text { loosening at follow-up }\end{array}$ \\
\hline $\begin{array}{l}\text { Tew and } \\
\text { Waugh } \\
{[4]}\end{array}$ & 1985 & $\begin{array}{l}1970- \\
1984\end{array}$ & $0.5-9 \mathrm{yrs}$ & 428 knees & $\begin{array}{l}\text { All TKAs, excluding all } \\
\text { hinge prosthesis }\end{array}$ & $\begin{array}{l}\text { Freeman, Sheehan, } \\
\text { Manchester, } \\
\text { Oxford, Kinematic } \\
\text { prostheses }\end{array}$ & $\begin{array}{l}\text { Clinical coronal } \\
\text { tibiofemoral angle } \\
\text { using special } \\
\text { goniometer with } \\
\text { fully-extended } \\
\text { arms placed on } \\
\text { defined marker } \\
\text { points at hip, knee, } \\
\text { and ankle; many } \\
\text { different surgeons }\end{array}$ & $\begin{array}{l}\text { 1) Removed because of pain } \\
\text { or radiographic evidence of } \\
\text { technical failure, loosening, } \\
\text { bony destruction; } \\
\text { 2)Prosthesis painful, but not } \\
\text { removed because no } \\
\text { technical failure or patient } \\
\text { unfit or unwilling to undergo } \\
\text { an operation }\end{array}$ \\
\hline $\begin{array}{l}\text { Lewallen, } \\
\text { et al. }[5]\end{array}$ & 1984 & $\begin{array}{l}1970- \\
1971\end{array}$ & $10 \mathrm{yrs}$ & $\begin{array}{l}209 \text { knees, } \\
159 \\
\text { patients }\end{array}$ & $\begin{array}{l}67 \% \text { RA, } 26 \% \text { OA, } 4 \% \\
\text { post-traumatic arthritis }\end{array}$ & $\begin{array}{l}\text { Polycentric TKA } \\
\text { at Mayo Clinic }\end{array}$ & Radiographs & $\begin{array}{l}\text { 1) Reoperation for any } \\
\text { reason; 2) unacceptable pain } \\
\text { or function }\end{array}$ \\
\hline $\begin{array}{l}\text { Bargren, } \\
\text { et al. [6] }\end{array}$ & 1983 & $\begin{array}{l}1971- \\
1975\end{array}$ & $5.5-9 \mathrm{yrs}$ & 32 knees & $\begin{array}{l}\text { Reliable patients who } \\
\text { faithfully attended follow- } \\
\text { up clinic }\end{array}$ & $\begin{array}{l}\text { Freeman-Swanson } \\
\text { (ICLH); small-area } \\
\text { tibial components; } \\
\text { no soft tissue } \\
\text { release to balance } \\
\text { ligaments; } \\
\text { attempted to obtain } \\
\text { alignment at } 0^{\circ} \text {; no } \\
\text { alignment device } \\
\text { used }\end{array}$ & $\begin{array}{l}\text { Radiographs of } \\
\text { first standing AP } \\
\text { and lateral after } \\
\text { operation ( } 6 \\
\text { weeks) }\end{array}$ & $\begin{array}{l}\text { Required revision for } \\
\text { loosening or instability; had } \\
\text { pain at time of evaluation } \\
\text { because of loosening or } \\
\text { instability }\end{array}$ \\
\hline $\begin{array}{l}\text { Gibbs, } \\
\text { et al. [7] }\end{array}$ & 1979 & $\begin{array}{l}1972- \\
1975\end{array}$ & $2-6 \mathrm{yrs}$ & $\begin{array}{l}78 \text { knees; } \\
68 \\
\text { surviving } \\
\text { knees at } \\
\text { time of } \\
\text { study }\end{array}$ & 59 with RA, 5 with OA & $\begin{array}{l}\text { Freeman-Swanson } \\
\text { (ICLH) Mark I }\end{array}$ & Radiographs & $\begin{array}{l}\text { Delayed sepsis, loosening of } \\
\text { tibial component, pain, } \\
\text { painful instability, } \\
\text { inadequate flexion, gross } \\
\text { tilting of femoral component, } \\
\text { patient dissatisfaction }\end{array}$ \\
\hline
\end{tabular}




\section{Tibio-Femoral Angle vs. P (Revision)}

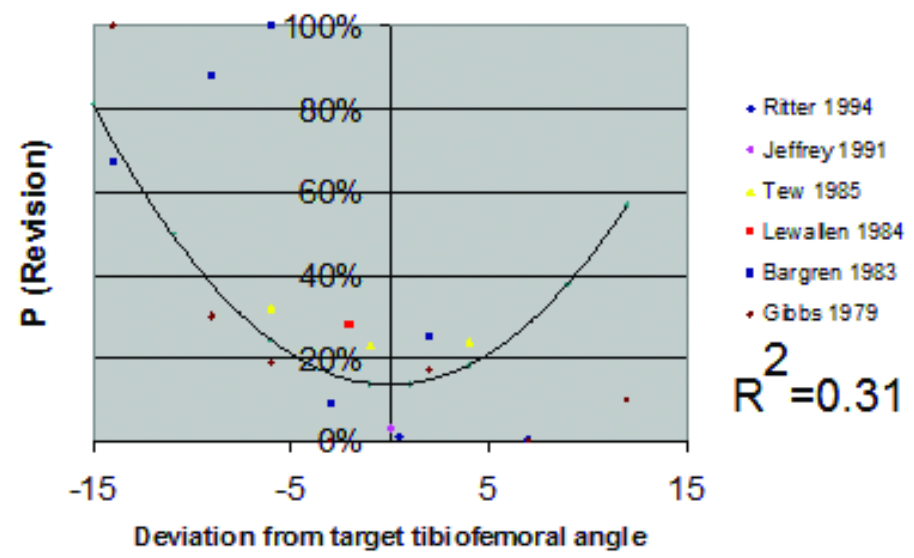

Fig. (1). A plot of the deviation from the ideal angle versus the probability of revision. Valgus angles are noted as positive values, and varus angles are noted as negative values. Any varus alignment and extreme valgus alignments correlated with an increased percentage of prosthetic failure and higher revision rates. A quadratic curve was fit to the data using a least-squares method. This curve has a vertical offset that represents a baseline probability of revision due to other patient characteristics that are independent of the alignment.

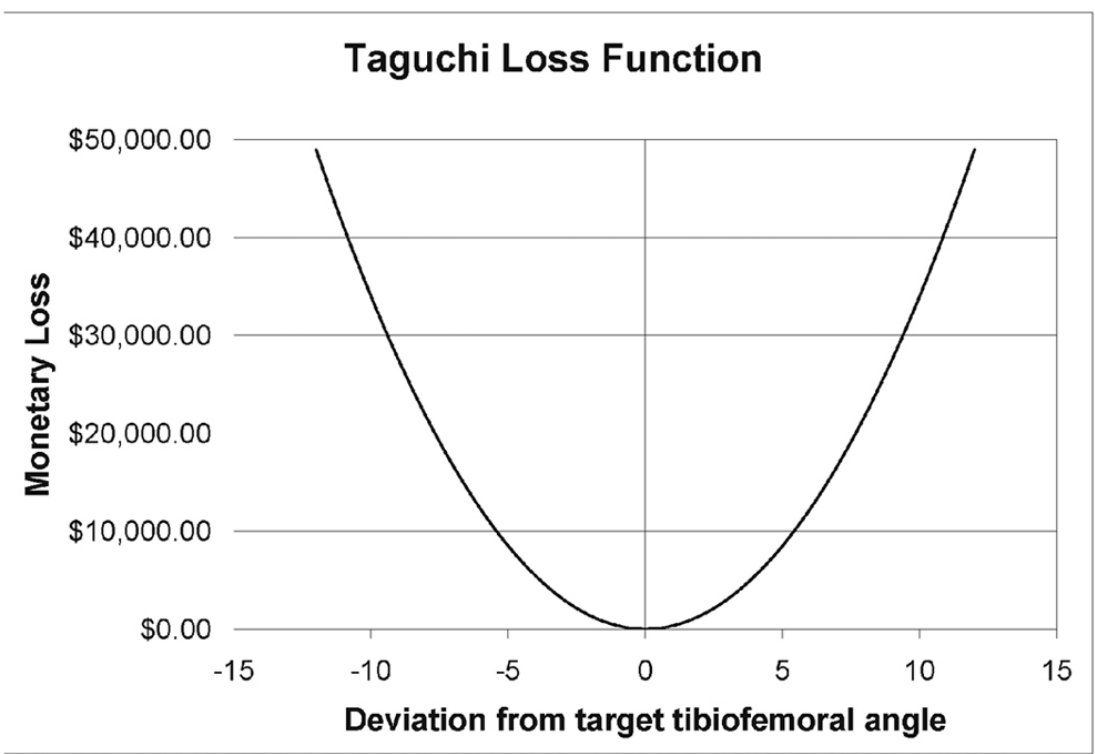

Fig. (2). The Taguchi loss function. The loss function is derived from the plot in Fig. (1). The monetary loss is derived from the probability of revision and the total hospital costs for an aseptic revision surgery. As the TKA deviates from the target alignment, the hospital incurs an increasing monetary cost.

an increasing monetary cost, since the hospital is charged with the cost of the revision surgery.

From the Taguchi loss function, the expected loss in a surgical population from a distribution of prosthesis angles can further be calculated. The expected loss is

$$
E(L)=\$ 326.80\left[\bar{y}^{2}+\mathrm{s}^{2}\right]
$$

where $\bar{y}$ is the mean deviance from the ideal varus/valgus angle and $s^{2}$ is the variance in varus/valgus angle.

\section{DISCUSSION}

The purpose of this study was to develop a tool that can be used by a biomedical engineer in the design stage of new orthopaedic technologies to improve TKA surgery. Taguchi's quality engineering methods are based on the concept of loss and expected loss functions, which link variation to the cost to society. This study presents loss and expected loss functions for tibiofemoral angles in TKA surgery.

The significance of the Taguchi loss function to biomedical designers lies in its ability to relate design decisions to cost outcomes for users of the device. For example, one option available to companies marketing TKA navigation systems is to move away from unreliable methods for determining mechanical axes of the knee to methods based on the helical axis of knee motion [9]. The loss function could be used to aid in management and 
engineering decisions about whether to implement a kinematically-based method of intra-operative axis determination that provides lower variability than manual digitization of landmarks by the surgeon.

The method can also be used to estimate the benefit to society of adopting computer-navigation for TKA. The mean malalignment of conventional TKA has been reported to be 2.6 degrees of valgus from the ideal angle, with a standard deviation of 1.7 degrees [10]. The mean malalignment of the computer-navigated TKA has been reported to be 1.4 degrees of valgus from the ideal angle, with a standard deviation of 0.8 degrees [10]. Using the expected loss equation, the expected loss from the conventional TKA is $\$ 3,154$, whereas the expected loss from the computernavigated TKA is $\$ 850$. The average savings of computernavigated TKAs is $\$ 2,304$ per knee due to the increase in accuracy and decrease in variation. For comparison, Dong and Buxton [11] used a Markov health-state model to estimate the per case benefit to be $£ 583$, which would be $\$ 1026$ in US dollars based on an exchange rate at the date of publication.

The development of a Taguchi loss function for total knee arthroplasty has several limitations. First, only varus and valgus malalignments were used in determining the expected loss function and average savings. Second, the coefficient of multiple determination was not high (0.31). Third, the older data used in the model development may not represent the failure rate of newer implant designs. Fourth, the study used only in-hospital costs in the calculation of the loss function. Data for the total cost to society of revision total knee arthroplasties were not available. Thus, hospital costs are used as an approximation for cost to society.

\section{CONCLUSIONS}

A critical insight of Taguchi's theory is that the total expected cost can be reduced by moving the mean closer to the target and reducing variance. Thus, even if the average prosthetic component is aligned properly, cost reductions can be obtained by reducing the variance of the alignment. Variance reduction is a central goal of quality engineering, and Taguchi's expected loss function highlights how reducing variance can reduce cost to society without changing the mean deviation from an ideal value. A loss function is now available for analyzing tibiofemoral angles in total knee arthroplasty.

\section{ACKNOWLEDGEMENTS}

The authors would like to thank Kristi Overgaard for her careful editing and formatting of this manuscript.

\section{REFERENCES}

[1] W.Y. Fowlkes, and C.M. Creveling, Engineering Methods for Robust Product Design. Reading, MA: Addison-Wesley, 1995, pp. 34-51.

[2] M.A. Ritter, P.M. Faris, E.M. Keating, and J.B. Meding, "Postoperative alignment of total knee replacement. Its effect on survival", Clin. Orthop., vol. 299, pp. 153-156, Feb. 1994.

[3] R.S. Jeffery, R.W. Morris, and R.A. Denham, "Coronal alignment after total knee replacement”, J. Bone Joint Surg. Br., vol. 73B, pp. 709-14, Sept. 1991.

[4] M. Tew, and W. Waugh, "Tibiofemoral alignment and the results of knee replacement", J. Bone Joint Surg. Br., vol. 67, pp. 551-556, Aug. 1985 .

[5] D.G. Lewallen, R.S. Bryan, and L.F. Peterson, "Polycentric total knee arthroplasty. A ten-year follow-up study", J. Bone Joint Surg. Am., vol. 66, pp. 1211-1218, Oct. 1984.

[6] J.H. Bargren, J.D. Blaha, and M.A. Freeman, "Alignment in total knee arthroplasty. Correlated biomechanical and clinical observations", Clin. Orthop., vol. 173, pp. 178-183, March 1983.

[7] A.N. Gibbs, G.A. Green, and J.G. Taylor, "A Comparison of the Freeman/Swanson (ICLH) and Waldius prosthesis in knee replacement", J. Bone Joint Surg. Br., vol. 61B, pp. 358-361, Aug. 1979.

[8] C. Lavernia, D.J. Lee, and V.H. Hernandez, "The increasing financial burden of knee revision surgery in the United States", Clin. Orthop., vol. 446, pp. 221-226, May 2006.

[9] L.C. Doro, R.E. Hughes, J.D. Miller, K.F. Schultz, B. Hallstrom, and A.G. Urquhart, "The reliability of a kinematically-derived axis of the knee versus digitized anatomical landmarks using a knee navigation system", Open Biomed. Eng. J., vol. 2, pp. 52-56, 2008.

[10] G. Matziolis, D. Krocker, U. Weiss, S. Tohtz, and C. Perka, "A prospective, randomized study of computer-assisted and conventional total knee arthroplasty. Three-dimensional evaluation of implant alignment and rotation", J. Bone Joint Surg. Am., vol. 89A, pp. 236-243, Feb. 2007.

[11] H. Dong, and M. Buxton, "Early assessment of the likely costeffectiveness of a new technology: A Markov model with probabilistic sensitivity analysis of computer-assisted total knee replacement", Int. J. Technol. Assess Health Care, Vol. 22, pp. 191-202, 2006 